\title{
An Evaluation Model and Empirical Study of Distributors' Performance in Chinese Mobile Industry
}

\author{
Hua Song ${ }^{1}$, Ying $\mathrm{He}^{2}$ and Zuohao $\mathrm{Hu}^{3}$ \\ ${ }^{1}$ School of Business, Renmin University of China, Beijing 100872, P.R. China \\ Songhua69@263.net \\ ${ }^{2}$ School of Management, Beijing University of Posts and Telecommunication, Beijing \\ 100876, P.R. China Heyingen2001@yahoo.com.cn \\ ${ }^{3}$ School of Management, Tsinghua University, Beijing 100084, China \\ huzh@em.tsinghua.edu.cn
}

\begin{abstract}
Distribution in China bas been undergoing great challenges nowadays. Circumstances such as how to evaluate distributor performance have become a critical issue in supply chain management. This paper proposes a Performance Value Index Model based on literary review and analysis of Chinese enterprises. It also validates the correlation among process, relational, and operational performances, financial benefits and potential competitive benefits by using SEM (Structural Equation Model). The results show that process performance and relational performance have positive effects on competitive potential while operational performance has great influence on both financial benefit and competitive potential. Simultaneously, potential competitiveness also positively relates to financial benefit.
\end{abstract}

Keywords: Supply chain management, Business performance monitoring, InterEnterprise collaboration, Strategic enterprise management

\section{INTRODUCTION}

In today's supply chain management, distributors differ from traditional ones. These distributors play an indispensable role by providing value-added services in logistics, transportation, inventory management, and information management service [1]. How to evaluate distributor performance effectively becomes a valuable topic in theoretical research. Many scholars have conducted research from different perspectives, yet previous studies in this area were inadequate, previous research discusses distribution performance from various perspectives. However more extensive research is required to determine how to integrate different performance dimensions more systematically and to determine how to combine these dimensions with characteristics of logistics of distributors. Moreover, previous research fails to link financial performance with strategic performance, thus lacking systematic consideration. This article explores the currently developing model of distribution in China, and proposes a performance measurement system for distribution based on a review of previous research studies, and empirical observations of distribution in the Chinese mobile industry.

Please use the following format when citing this chapter:

Song, H., He, Y., Hu, Z., 2007, in IFIP International Federation for Information Processing, Volume 255, Research and Practical Issues of Enterprise Information Systems II Volume 2, eds. L. Xu, Tjoa A., Chaudhry S. (Boston: Springer), pp. 1463-1471. 


\section{DISTRIBUTOR AND DISTRIBUTION PERFORMANCE MEASUREMENT}

\section{1 Literature Review}

Being a key component of measuring supply chain performance, a distributor's performance has a direct impact on the operational efficiency of supply chain. Thus, if a firm can effectively measure the performance of its distributors, the overall efficiency of its distribution channel will be improved. However, distributor behavior and channel performance are often complex, therefore it needs to be measured from various dimensions. Previous research on distributor performance typically addresses three aspects: the process performance, which is the influence of distribution service on performance within a channel; the relational performance, which is the influence of power, conflict, and commitment on distribution performance within a distribution channel; the operational performance, which study of distribution performance from the perspective of supply chain integration.

Process performance (PP) reflects the performance shown by the inner management activity process in each distribution stage, including the flexibility (FLE), responsiveness (RES), and information managing capability (IHC) of the distribution system [2-3]. But the input degree of distribution resources has rarely been mentioned in most distribution performance research. The studies of Cox et al. mention that in the preliminary stage, various resources committed by the suppliers and the distributors influence the capability and desire to achieve performance objectives, and this outcome will influence subsequent resource commitment as well as direct and indirect performance [4]. Therefore, the degree of input (DIS) needs to be considered when measuring distribution process performance. Sales \& Operations Planning (S\&OP) is another factor that needs to be considered. S\&OP is also a process factor through which the firm's departments of sales, marketing, finance, and operations together create annual forecasts as close to actual demand as possible to fulfill operational goals [5].

Relational Performance (RP) mainly reflects the relationship between the distributor and the supplier. Specific Assets Investment (SAI) was regarded as a means to stabilize the supply chain structure and achieve desirable distribution performance [6]. Trust is another significant measuring dimension in relational systems [7-8]. It is not only generated from the trust of the supplier in distribution (TOD), but it is also shown as the trust of the distributor by its supplier (TOS). Such bilateral trust has an effect on mutual commitment and mutual influence [9]. Dyer indicates that continuity of the relationship and Knowledge Transfer and Information Sharing (KTS) also improve performance[10-11], while the continuity of relationship is decided by the degree of impartiality of benefits (IOB) [12], the degree of mutual communication ( CCP ) [13], and the degree of influence of the supplier's operation (ISO) [14]. Those factors together form the relational performance dimensions.

Service operation performance (OP) measures the distribution performance by the external performance of the distribution operation, which reflects the distribution 
operation status. Through negotiation, the supplier and the distributor form a competitive price, which directly influences the inter-supplier relationship and the distributor's performance (COP) [14]. Besides competitive price, product portfolio and competitiveness influences integrated distribution operational performance. In the firm's supply chain structure, product factors have great influence on it. Therefore, Product Portfolio and Competitiveness mirror supply chain operation (PPC) [15]. In previous researches, Availability (AIM) and Cycle Time (CYT) are believed to reflect the supply chain operation [16]) . Recently, Capital Management has been drawing attention, especially for distribution and logistics firms. From financial management to cash flow, the effective management of each capital process is highly influential on reducing risk, accelerating cash flow, and enhancing supply chain performance [1718]. Thus Capital Management (CMF) is also a significant dimension in supply chain operational performance.

\subsection{The Structural Model of Distribution Performance}

The outcome of distribution mainly reflects the economic performance of distributors' supply chain operations. Such benefits not only yield financial benefits, but also as potential competitive benefits. Traditional financial benefits (FB) mainly refer to factors such as sales income (SAR) and profits (PRR). However, when considering the process of supply chain transformation and product distribution processes, the temporary sales income and profits are inadequate. Comparatively, long-term or non-financial benefits should also be considered. Hence, Customer Volume Realization (CUS) and Distributor Risk Reduction (DIR) are used to reflect the financial performance of the distributor. Potential Competition Benefits (PCB) reflects the expectation of future and potential of the firm's development. This factor is measured by three indices; Expectation for Future Development (EFD), which is the firm's commitment for its future development, Expectation for Partnership (EFP), and the distributor's willingness to input for the future development (IFF).

When considering behavioral factors of distribution performance, three aspects in previous research reflect the measurement system of performance: distribution service factors, relational factors of the distribution process, and integrated factors of process operations. The authors believe that these factors can be categorized into Process Performance (PP), Relational Performance (RP), and Operation Performance (OP). These three factors should be closely integrated to determine behavioral factors of a firm's performance, for the reason that $\mathrm{PP}$ strengthens the firm performance from its inner management and operation, $O P$ realizes the firm's performance from its exterior management, and RP forces and ensures the realization of performance through harmonizing and collaborating between firms. When all of these factors are realized, a firm's competitiveness and value realization could be enhanced. Thus factors of these three aspects co-decide Potential Competitive Benefits and Financial Benefits: 


$$
\sum_{i=1}^{n} w_{i} P C B_{i}=\gamma_{21} \sum_{k=1}^{p} \varphi_{k} P P_{k}+\gamma_{22} \sum_{l=1}^{q} \varphi_{l} R P_{l}+\gamma_{23} \sum_{r=1}^{t} \varphi_{r} O P_{r}+\varepsilon_{s}
$$

$w_{i}$ is the weight of evaluation indices of competitiveness; $\varphi_{k}$ is the weight of evaluation indices of process performance; $\varphi_{i}$ is the weight of evaluation indices of relational performance; $\varphi_{\mathrm{r}}$ is the weight of evaluation indices of service operation performance; $\gamma_{21}$ is the weight of integrated process performance factors toward its potential competitiveness; $\gamma_{22}$ is the weight of integrated relational performance on potential competitiveness; $\gamma_{23}$ is the weight of integrated operation performance toward potential competitiveness.

$$
\sum_{j=1}^{m} w_{j} F B_{j}=\gamma_{11} \sum_{k=1}^{p} \varphi_{k} P P_{k}+\gamma_{12} \sum_{l=1}^{q} \varphi_{l} R P_{l}+\gamma_{13} \sum_{r=1}^{t} \varphi_{r} O P_{r}+\varepsilon_{V}
$$

$w_{j}$ is the weight of evaluation indices of financial value; $\varphi_{k}$ is the weight of evaluation indices of process performance; $\varphi_{i}$ is the weight of evaluation indices of relational performance; $\varphi_{\mathrm{r}}$ is the weight of evaluation indices operation performance; $\gamma_{11}$ is the weight of integrated process performance factors on financial value; $\gamma_{12}$ is the weight of integrated relational performance on financial value; $\gamma_{13}$ is the weight of integrated operational performance on financial value.

\section{METHODOLOGY AND DATA COLLECTION}

\subsection{Data Collection and Reliability}

The empirical test is based on a survey, which was conducted from September 2004 to February 2005. Targeting mobile distributors in China, 773 questionnaires were sent out, of which 508 responded. The response rate was $65.7 \%$. Among the questionnaires returned, 73 copies are incompletely filled or contained obvious errors. These were considered to be of no effect and omitted. The final effective count of questionnaires was 435 copies, and the response rate was $56.2 \%$. The basic sample framework of this survey was followed. Respondents are primarily mobile distributors in China. Most of them were sent by mail. Lost information is checked by telephone or EMS. Firms by type consist of Ltd.(46.4\%), small individual firms $(31.3 \%)$, private firms $(15.4 \%)$, and state-owned firms $(4.6 \%$.).

Variable measurement was designed by selecting indices based on our review. All questions were to be answered on a scale from "completely disagree" to "completely agree" based on Likert's five-point scale. The survey was taken a pilot-test in several companies, so that adjustments could be made according to the pre-test. To prove the influence of different behavioral factors on ultimate performance and competitiveness, we tested the data by structuring an equation based on the theoretical model we developed, using Lisrel software. The Cronbach's a value of Process 
Performance, Relational Performance, Operational Performance, Financial Benefits, and Potential Competitive Income are respectively $0.831,0.787,0.753,0.724,0.745$. According to Devellis and Nunnally, in Social Sciences, if Cronbach's a value is above 0.7 , the data is highly reliable. In this research, the minimum value of a is 0.724 , and the maximum value is 0.831 . So, it can be concluded that the data of this research is reliable.

\subsection{Data validity and Structure Model Analysis}

Data validity indicates that variables are highly distinguishable. When different indices are used to measure the same variable, and these indices are closely related, the data have good validity. Carr and Pearson point out that when the data have assembled effectiveness, they have two characters: one is that the value of $T$ is above 2 (when the confidence interval is $95 \%$, or when $\mathrm{a}=0.05, \mathrm{~T}=1.96$, the statistical test is significant, the approximate value of 1.96 is 2); the other is when the $R^{2}$ is above 0.3 [19]. The CFA test indicates that in the factor loading of most indices in this model, $T$ is between 5.90 and 27.79. $\mathrm{R}^{2}$ are above 0.3 , but the $\mathrm{R}^{2}$ of Specific Assets Investment is only 0.079 . It means that Specific Assets Investment cannot reflect the relational performance between the distributor and the supplier. Impartiality of Benefits and the explanations of benefits toward relational performance also are limited. Hence, after omitting these two indices, the authors used Lisrel to make a structure equation test.

When $\mathrm{X}^{2} / \mathrm{df}<2$, the total strength of fit is better, when it is between 2.0 to 5.0 , it can be accepted that $\mathrm{X}^{2} / \mathrm{df}=3.39$, which is acceptable. Since this index is easily influenced by the sample capacity, it is not very meaningful to completely use this index [20]. Other major indices of this model evaluation are RMSEA, the value of which is considered to be good when below 0.08. There are also CFI, IFI and NNFI. When the values of these indices are equal to or above 0.9 , the model is good for observing data [21]. The indices of this model satisfy the requirements. The causal relationship of each of the variables and the analytical results of the related relationship of the Lisrel analyses are shown in Table 1, Model 1.

Table 1. Structure Model Analyses Results

\begin{tabular}{|c|c|c|c|c|c|}
\hline \multirow{2}{*}{$\begin{array}{l}\text { Relationship } \\
\text { between } \\
\text { variables }\end{array}$} & \multirow[t]{2}{*}{ Coefficient } & \multicolumn{2}{|c|}{ Model 1} & \multicolumn{2}{|c|}{ Model 2} \\
\hline & & $\begin{array}{l}\text { Loading } \\
\text { Value }\end{array}$ & $\begin{array}{c}\text { T } \\
\text { Value }\end{array}$ & $\begin{array}{l}\text { Loading } \\
\text { Value }\end{array}$ & $\begin{array}{c}\mathrm{T} \\
\text { Value }\end{array}$ \\
\hline$\xi_{1} \rightarrow \eta_{1}$ & $\gamma_{\mathrm{I} 1}$ & -0.05 & -0.72 & - & - \\
\hline$\zeta_{1} \rightarrow \eta_{2}$ & $X, 1$ & 0.33 & 3.64 & 0.33 & 3.66 \\
\hline$\zeta_{2} \rightarrow \eta_{1}$ & $\gamma_{12}$ & 0.10 & 1.46 & - & - \\
\hline$\zeta_{2} \rightarrow \eta_{2}$ & $\gamma_{22}$ & 0.37 & 5.01 & 0.38 & 5.10 \\
\hline$\zeta_{3} \rightarrow \eta_{1}$ & $\mathrm{\gamma} 1: 3$ & 0.74 & 8.12 & 0.72 & 8.60 \\
\hline$\zeta_{3} \rightarrow \eta_{2}$ & $y=$ & 0.16 & 2.20 & 0.15 & 2.12 \\
\hline$\eta_{2} \rightarrow n_{1}$ & $\beta_{12}$ & 0.15 & 1.80 & 0.19 & 2.92 \\
\hline$\zeta_{1}-\zeta_{2}$ & $\Phi_{21}$ & 0.33 & 6.40 & 0.33 & 6.40 \\
\hline$\zeta_{2}-\zeta_{3}$ & $\phi_{32}$ & 0.28 & 4.50 & 0.30 & 4.83 \\
\hline$\overline{\bar{s}_{1}}-\bar{\zeta}_{3}$ & $\phi_{31}$ & 0.58 & 11.70 & 0.57 & 12.00 \\
\hline
\end{tabular}


According to the results of Table 1 , Model 1 , when $\alpha=0.05, T$ value of the two coefficients $\xi 1 \rightarrow \eta 1$ and $2 \rightarrow \eta 1$ are not significant, which indicates that these two relationships are not strong. After removing these two variables, the authors tested the structure equation by using Lisrel. $T$ values were all significant when $\alpha=0.05$ (see Table 1, Model 2). According to the analytical results of Table1, Model 2, each regression formula and $R^{2}$ of the causal relationship model are shown in Table 2.

Table 2. Regression Formulas and Their $\mathbf{R}^{2}$

\begin{tabular}{cc}
\hline regression equation & $\mathrm{R}^{2}$ \\
\hline$\eta_{1}=0.19 \eta_{2}+0.72 \zeta_{3}$ & 0.66 \\
\hline$\eta_{2}=0.33 \zeta_{1}+0.38 \zeta_{2}+0.15 \zeta_{3}$ & 0.44 \\
\hline$\eta_{1}:$ Financial Benefits; $\eta_{2}:$ & Potential Competitive Benefits; $\zeta_{1}:$ \\
Relational Performance ; $\zeta_{2}: \quad$ Process Performance ; $\zeta_{3}:$ 0peration
\end{tabular}

Performance

The result indicates that: (1) the Relational Performance has significant direct influence on Potential Competitive Benefits $\left(\gamma_{11} ;\right.$ (2) Process Performance (the implementation of the firm's supply chain process) has significant direct influence on the formation of Potential Competitiveness $\left(\gamma_{22}\right)$; (3) operation of a firm's supply chain has significant direct influence on Financial Benefits $\left(\gamma_{13}\right)$ and Potential Competitiveness $\left(\gamma_{s i}\right)$, especially on Financial Benefits; (4) Potential Competitive Benefits has significant direct influence on the formation of Financial Benefits ( $\beta_{12}$ (5) Relational performance and Process Performance have significant influence on Financial Benefits, though such influence is exhibited as indirect; (6) Relational Performance, Process Performance and Operation Performance are interrelated ( $\varphi_{21}$ $\left.\varphi_{32} \varphi_{31}\right)$. The improvement of Relational Performance positively strengthens Operation Performance, and the enhancement of Operation Performance strengthens Relational Performance. In relationships between Process Performance and Operation Performance, and Relational Performance and Process Performance, both have strong positive inter-influences (See figure 1).

\section{CONCLUSION, IMPLICATION AND LIMITATION}

Theoretically, this research extends formative mechanisms and approaches of the distributor's performance in China, and provides beneficial reference on how to effectively implement distribution management for Chinese distribution firms. Conclusions and explanations could be made as follows: (1) The degree of Specific Assets Investment has no direct influence on the establishment and maintenance of the inter-firm relationship. Capital Assets Investment and Physical Assets Investment cannot ensure the long-term collaborative relationship between the distributor and the supplier. Conversely, the continual communication, information and knowledge share, trustworthiness, and the support and/or participation of the distributor to the supplier's business have great influence on relational performance. After conducting further surveys, the authors found that there are two reasons for the occurrence of such phenomena: first, the Capital Investment cannot ensure the maintenance and development of the relationship. At the same time, if the distribution service operation 
and process are not improved, it will result in large investment waste, and benefits cannot be secured; second, the Capital Assets Investments are usually not in large quantities in the Mobile industry distribution, and the distributors are not likely to distribute a single product. Therefore, the Specific Assets Investment is relatively weak.

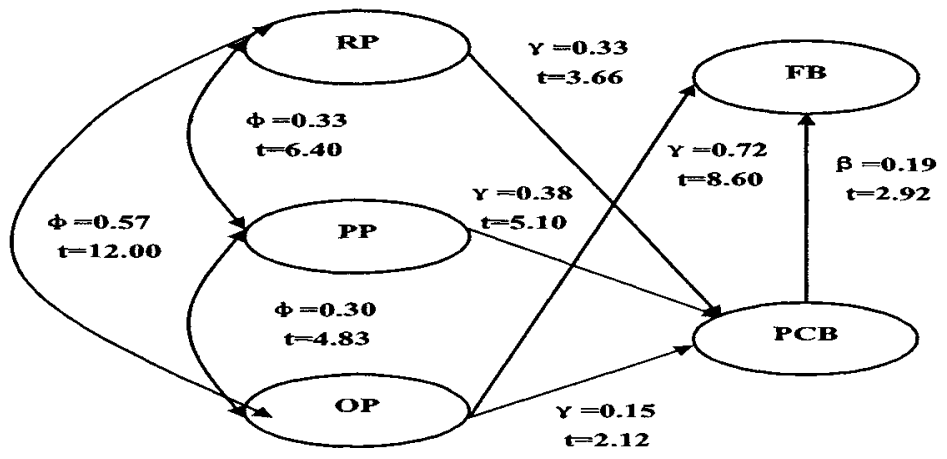

Figure 1. Distribution Performance Structure Equation Model

(2) From the model test, positive influence of the relational performance on Financial Benefits is not proven this indicates that the good supply-distribution relationship has no direct influence on the company's financial benefits. It is likely that the relational performance is a long-term investment, which creates interdependence and harmony. This produces knowledge and assets that extends beyond a single organization. So, performance does not show as short-term financial benefits, but as long-term potential competitiveness, and finally pushes financial performance through competitive performance.

(3) The distribution system's flexibility, distribution resources, network input, customer response, formation of information managing capability, and effective supply-demand correspondence are key factors for developing the distributor's process. The development of these factors has direct influence on a firm's potential competitiveness and future development capacity. However, it has no direct influence on financial performance. This is because these factors are the firm's inner resources and capacity. Since the formation of firm's resources and capacity forms the firm's potential strategic competitiveness, such capacity has indirect influence on Financial Benefits.

(4) The distribution service operation activities and related performance management like product availability, competitive price, cycle time, capital management capacity and product portfolio and competitiveness directly reflect the combined degree of business flow, logistics, capital flow, and information flow in the distribution firm's supply chain. These factors are interdependent and directly determine the distribution firm's operational and financial benefits, and have distinctive functions on the formation of the firm's potential competitiveness.

(5) For distribution firms, the construction of processes and resources, the establishment of the supply-distribution system and service operation management are 
three closely linked behavioral performance factors. In fact, good supply-demand relationships can improve the firm's inner management and external operations. Meanwhile the development of the latter two can strengthen and stabilize the trust between the supplier and the distributor. The improvement of the firm's process performance lays a stable foundation for service operation enhancement, while good service can facilitate the further development of processes. Therefore, the combination of the three exogenous variables in the model co-influences the firm's Financial Benefits and Potential Competitiveness. Lacking in any of these aspects will cause the firm to sacrifice its distribution performance.

Two aspects in this research need to be further developed, which also constitutes the limitations of this research: first, the sample of this research mainly comes from the distributors of the mobile industry. Thus the performance evaluation mainly focuses on the distributors' performance. However, in supply chain distribution, the distribution performance evaluation should not only focus on distributors, but also on the supplier providing products and service. Additionally, within the further study, objects should be expanded and model effectiveness tests and relative performance realization approaches should also be processed from the supplier's perspective. Difference analysis should be made based on these, and then causes should be explored. The second aspect refers to the fact that this performance evaluation model is a total model. Many factors in it such as the three aspects of the exogenous variables still need to be analyzed further and in detail. These are all issues that need to be further explored in future research.

\section{REFERENCES}

1. T. Rajesh and D.Chandrasekhar, A methodology for cost versus service trade-offs in wholesale location-distribution using mathematical programming and analytic hierarchy process, Journal of Business Logistics. Volume 18, Number 2, pp.77-98, (1997).

2. A.J. Magrath and K.G. Hardy, Selecting sales and distribution channels, Industrial Marketing Management. Volume 16, Number 4, pp.273-278, (1987).

3. R.S. James and M.L. Douglas, Strategic Logistics Management (McGraw-Hill Companies, Inc, 2001).

4. E.C. Amy and O.C. Walker, Reaction to disappointing performance in manufacturerdistributor relationships: the role of escalation and resource commitments, Psychology \& Marketing. Volume 14, Number 8, pp.791-821, (1997).

5. F. Smith, Plan with the big 'S', MSI. Volume 22, Number 11, pp.42, (2004).

6. B. Klein, R.G. Crawford, and A.A. Alchian, Vertical integration, appropriable rents, and the competitive contracting process, Journal of Law and Economics. Volume 21, pp.297326, (1978).

7. R.M. Morgan and S.D. Hunt, The commitment-trust theory of relationship marketing, Journal of Marketing. Volume 58, Number 4, pp.20-38, (1994).

8. J.H. Dyer and W. Chu, The role of trustworthiness in reducing transaction costs and improving performance: Empirical Evidence from the United States, Japan and Korea, Organization Science. Volume 14, Number 1, pp.57-68, (2003).

9. L.J. Frank and R. Reed, Trust and adaptation in relational contracting, The Academy of Management Review. Volume 25, Number 4, pp.837-882, (2000).

10. J.H.O. Dyer and G. William, Japanese-Style Partnerships: Giving Companies a Competitive Edge, Sloan Management Review. Volume 35, Number 1, pp.51-63, (1993). 
An Evaluation Model and Empirical Study of Distributors' Performance in Chinese Mobile

Industry 1471

11. J.H. Dyer, D.S. Cho, and W. Chu, Strategic supplier segmentation: The next "best practice" in supply chain management, California Management Review. Volume 40 , Number 2, pp.57-77, (1998).

12. R.C. Lamming, N.D. Caldwell, D.A. Harrison, and W. Phillips, Transparency in supply relationships: Concept and practice, Journal of Supply Chain Management. Volume 37, Number 4, pp.4-10, (2001).

13. J.J. Mohr, R.J. Fisher, and J.R Nevin, Collaborative communication in inter-firm relationships: Moderating effects of integration and control, Journal of Marketing. Volume 60, Number 3, pp.103-115, (1996).

14. M. Tracey and L.T. Chong, Empirical analysis of supplier selection and involvement, customer satisfaction, and firm performance, Supply Chain Management: An international Journal. Volume 6, Number 4, pp.174-188, (2001).

15. S.A. Moon, The Relationships Among Manufacturer Product Strategy, Supply Chain Structure and Supply Chain Inventory, Asia Pacific Journal of Marketing and Logistics. Volume 16, Number 2, pp.20-45, (2004).

16. J.B. Donald, D.J. Closs, and M.B. Cooper, Supply Chain Logistics Management (McGraw-Hill Companies, 2002), pp.75-76.

17. T.W. Speh and R.A. Novack, The management of financial resources in logistics, Journal of Business Logistics. Volume 16, Number 2, pp.23-42, (1995).

18. J. Geunes and P.M. Pardalos, Network Optimization in Supply Chain Management and Financial Engineering: An Annotated Bibliography, Networks. Volume 42, Number 2, pp.66-84, (2005).

19. A.S. Carr and J.N. Pearson, Strategically management buyer-supplier relationship and performance outcome, Journal of Operations Management. Volume 17, pp.497-519, (1999).

20. J. Hou, Z. Wen, and Z. Cheng, Structural Equation Model and Its Application (Scientific and Educational Press, 2004).

21. P.M. Bentler and D.G. Bonett, Significance tests and goodness - of- fit in the analysis of covariance structures, Psychological Bulletin. Volume 88, pp.588-606, (1980). 